smoking cessation centres, with success rates much the same as those obtained with nicotine chewing gum. ${ }^{17}{ }^{18}$ In hospital patients with smoking related diseases transdermal nicotine seems to confer little if any benefit over advice and support alone. Its value has yet to be proved when it is bought over the counter and used without any professional advice and support. The question of whether using both transdermal nicotine and nicotine chewing gum might improve cessation rates is worth answering, especially in heavy smokers.

I A CAMPBELL

Consultant in thoracic medicine

Llandough Hospital,

Cardiff,

South Glamorgan CF64 5YA

1 Rose JE, Herskovik JE, Trilling Y, Jarvik ME. Transdermal nicotine reduces cigarette craving and nicotine preference. Clin Pharmacol Ther 1985;38:450-6.

2 Buchkremer G, Bents H, Minneker E, Opitz K. Combination of behavioural smoking cessation therapy with transdermal nicotine substitution: long-term effects. In: Aoki M, Hisamichi S, Tominaga S, eds. Smoking and health. Amsterdam: Excerpta Medica, 1987:857-60. (International Congress Series No 780 .)

3 Buchkremer G, Minneker E, Block M. Smoking cessation treatment combining transdermal nicotine substitution with behavioural therapy. Pharmacopsychiatry 1991;24:96-102.
4 Abelin T, Buehler A, Muller P, Vesanen K, Imhof PR. Controlled trial of transdermal nicotine patch in tobacco withdrawal. Lancet 1989;i:7-9.

5 Hurt RD, Lauger GG, Offord KP, Kottke TE, Dale LC. Nicotine-replacement therapy with use of a transdermal nicotine patch - a randomised double-blind placebo-controlled trial. Mayo Clin Proc 1990;65:1529-37.

6 Daughton DM, Heatley SA, Prendergast J, Causey D, Knowles M, et al. Effect of transdermal nicotine delivery as an adjunct to low-intervention smoking cessation therapy. Arch Intern Med 1991;151:749-52.

7 Tonnesen P, Norregaard J, Simonsen K, Sawe U. A double-blind trial of a 16-hour transdermal nicotine patch in smoking cessation. N Engl f Med 1991;325:311-5.

8 Tonnesen $\mathrm{P}$, Norregaard J, Sawe U. Two-year outcome in a smoking cessation trial with a nicotine patch. Fournal of Smoking-Related Diseases 1992;3:241-5

9 Fiore MC, Jorenby DE, Baker TB, Kenford SL. Tobacco dependence and the nicotine patch. fAMA 1992;268:2687-94.

10 Transdermal Nicotine Study Group. Transdermal nicotine for smoking cessation. JAMA 1991;266:3133-8.

11 ICRF General Practice Research Group. Effectiveness of a nicotine patch in helping people stop smoking: results of a randomised trial in general practice. $B M \mathcal{F} 1993 ; 306: 1304-8$.

12 Russell MAH, Stapleton JA, Feyerabend C, Wiseman SM, Gustavsson G, Sawe U, et al. Targeting heavy smokers in general practice: randomised controlled trial of transdermal nicotine patches. BMF 1993;306:1308-12.

13 Campbell IA, Tjeder-Burton SM, Prescott RJ. Smoking cessation in hospital patients given repeated advice plus nicotine or placebo chewing gum. Respir Med 1991;85:155-7.

14 British Thoracic Society. Comparison of four methods of smoking withdrawal in parients with smoking-related diseases. $B M 7$ 1983;286:595-7.

15 British Thoracic Society. Smoking cessation in patients: two further studies by the British Thoracic Society. Thorax 1990;45:835-40.

16 Campbell IA, Prescott RJ, Tjeder-Burton SM. Nicotine patches v placebo in 234 hospital patients. Thorax 1992;47:886.

17 Raw M. Does nicotine chewing gum work? BMF 1985;290:1231-2.

18 Lam W, Sacks H, Sze P, Chalmers T. Meta-analysis of randomised, controlled trials of nicotine chewing gum. Lancet 1987 ;ii:27-9.

\title{
Overpopulation and overconsumption
}

\section{Combating the two main drivers of global destruction}

The great achievement of last year's "earth summit" in Rio de Janeiro lay less in what was agreed at the meeting and more in the debate that surrounded it. People came to understand much more clearly that environmental degradation could not be considered on its own: it must be considered together with overpopulation, poverty, development, excessive consumption, and relations between the rich and poor worlds. The great failure of the summit was that its final statement did not deal adequately with the two primary drivers of global destruction: overpopulation and overconsumption. The United States administration of George Bush, nervous of the coming election, vetoed references to overconsumption, and the Vatican and the antiabortion lobbies removed references to overpopulation.

Governments in all countries are understandably nervous of preaching too much on population. Governments in rich countries are reluctant to patronise poor countries, where $90 \%$ of population growth is occurring. Policy makers understand better than they did in the 1960s the complex factors that lead to population growth and the futility of concentrating too much on one issue. Many people are uneasy about the state interfering in this most intimate of decisions, particularly after some of the excesses seen in India and China. Politicians are reluctant to lose the votes of Catholics. Population experts remain embarrassed by some of the dire and inaccurate predictions of the 1960 s, and the media have become bored by the issue.

Yet we cannot allow ourselves to become bored by overpopulation. Population growth keeps people in poverty, obliges them to destroy their environments, and leads to deforestation, soil erosion, water shortages, and desertification. Current population growth results from death rates having fallen everywhere but birth rates having fallen only in the rich world. The world population will grow by at least another 2.5 billion by 2025 , but it's much more likely that the growth will be 3.5 billion or more. World population will probably top 8 billion in 2025, meaning that it will have grown fourfold in a century.

One response to this problem must be to keep population on the agenda at every level of public administration-from the United Nations to the village council. A recent meeting organised by Gresham College, the Commonwealth Foundation, and the Ciba Foundation looked at what could be done to keep attention focused on the issue. One way forward seems to be for professionals, including doctors, to play a larger part, particularly in groups consisting of more than one profession. Interprofessional collaboration is needed both to understand the problems better and to seek solutions to them. Such collaboration is also necessary, argued Sir Shridath Ramphal, former Commonwealth secretary general, to stop next year's world conference on overpopulation in Cairo being hijacked by pressure groups with very narrow agendas-as happened in Rio.

Professionals can also play a part in ensuring that people are put at the centre of the solution to overpopulation and that a particular focus is on women, the people who in most of the world prepare the food, collect the water, and play the major part in controlling fertility. Female literacy rates are desperately low in many parts of the developing world, yet literacy among women reduces infant mortality and fecundity. Increasing evidence shows that many women are crying out for access to contraceptives, and part of the solution to the overpopulation problem is to get contraceptives to them. The cost will be about $\$ 9$ billion annually, the amount the world spends on arms every 56 hours.

But, said Lord Porter, former president of the Royal Society, overconsumption of energy is as big a problem as overpopulation - and the two are unavoidably linked. While population grew from 1.49 billion in 1890 through 2.5 billion in 1950 to 5.32 billion in 1990 , energy consumption grew even faster, from 1 terawatt in 1890 through 3.3 terawatts in 1950 to 13.7 terawatts in 1990 . Energy consumption grows not only as population grows but also as poor people become richer. People in the developing world each use 0.28 kilowatts a year, while those in the developed world use 3.2 kilowatts and people in the United States 9 kilowatts. Energy consumption and standard of living are closely related, and Lord Porter thought that development for those in the poor world to a 
"modest Utopia" would mean consuming $2 \cdot 3$ kilowatts each a year. That means something like a sevenfold increase for the poor, which combined with a doubling of their numbers by 2050 would mean a 14-fold increase in their energy consumption. Yet, said Lord Porter, we have enough oil and gas to last something like 50 years at current rates of consumption and energy from nuclear fusion will not be widely available for half a century even if the reaction is achieved in the laboratory tomorrow. Furthermore, the rise in concentrations of carbon dioxide resulting from energy consumption is the cause of global warming.

Lord Porter was not in apocalyptic mood at the meeting, but he did make clear-as did others-that to survive we need to look at radical changes in our values and our lives. Conservation will have only a minuscule effect on energy consumption. In both the rich and poor worlds we must rethink how we transport ourselves, what we eat (Californian steak demands huge inputs of water, energy, and land), how many children we have, and how we live. The British, for instance, may currently have more public debate on infertility than fertility, but a country that contained 30 million rather than 56 million people would be less environmentally ravaged and make a smaller contribution to global destruction.

RICHARD SMITH

Editor

BMF, London WC1H 9JR

\section{Pre-employment chest radiography and NHS staff}

\section{Not needed for asymptomatic people with strongly positive tuberculin skin reactions}

Most people who have worked in the NHS will remember the ritual pre-employment chest radiograph. The Department of Health has endorsed this practice, ${ }^{1}$ which has continued in most districts until recently. Its main rationale is to detect cases of pulmonary tuberculosis. A review of recent evidence suggests, however, that routine pre-employment chest radiography of NHS staff is not an effective or efficient way of doing this.

In two series of routine pre-employment radiographs in the late 1980s abnormalities were rare, and no evidence of tuberculosis was found in nearly 3000 films. The authors recommended restricting pre-employment radiography to those people with strongly positive tuberculin skin tests. ${ }^{23}$ In 1990 a subcommittee of the joint tuberculosis committee of the British Thoracic Society recommended a pre-employment chest radiograph for NHS employees with a grade 3 or 4 Heaf reaction and for those with a grade 2 reaction without a BCG scar, taking such Heaf reactions as evidence of infection with tuberculosis. ${ }^{4}$ The aim was to reduce the number of preemployment chest radiographs.

But strongly positive tuberculin skin reactions are common among NHS employees with and without BCG scarss: NHS occupational physicians in London and Manchester estimated that perhaps half their new employees would require a chest radiograph using the British Thoracic Society's criteria. ${ }^{67}$ Given the very large clinical workforce of the NHS with its high turnover rate, the society's criteria require that each year thousands of new employees have pre-employment radiography. Is this justifiable? Are NHS employees with strongly positive skin tests really at an appreciable risk of having tuberculosis?

A case-referent study from London of employees who had routinely had pre-employment radiography found that abnormalities were rare ( 68 out of 5000 ). No excess of positive skin tests was found among those with abnormal radiographs compared with control subjects with normal radiographs. ${ }^{78} \mathrm{~A}$ recent study in the west midlands reviewed the working of the British Thoracic Society's recommendations during 1990-2. Among 8475 new staff, about $6 \%$ had grade 3 or 4 Heaf reactions, and therefore had radiography. There was no evidence of active tuberculosis on any of the films and only 3\% of them were abnormal in any way. A prospective study from London published in the BMJ last month confirmed that strongly positive skin tests in new hospital employees are common, whether or not a.BCG scar is present. ${ }^{10}$ On the basis of the British Thoracic Society's guidelines, over a third of the
640 new employees during one year had chest radiography; no cases of tuberculosis were detected.

These recent studies indicate that routine pre-employment chest radiography for people with strongly positive tuberculin skin reactions are of unproved value and should be stopped. So when is pre-employment chest radiography indicated? Nearly all cases of active pulmonary tuberculosis are symptomatic. ${ }^{11}$ A review of cases of tuberculosis in NHS staff found that most presented with symptoms, rather than being detected on routine annual radiography. ${ }^{12}$ Finding cases of active tuberculosis on routine pre-employment radiography among people not admitting to symptoms on direct questioning is very unlikely. Pre-employment health screening should include inquiries about symptoms suggestive of pulmonary tuberculosis, including persistent cough, unexplained weight loss, malaise, and night sweats. Radiographs should be reserved for symptomatic people. This will save time and money and avoid unnecessary irradiation of healthy people.

ANNE COCKCROFT

Occupational Health Unit, Consultant

Royal Free Hospital,

London NW3 2QG

1 Department of Health and Social Security. Health service management: control of tuberculosis in NHS employees. London: DHSS, 1978. (HC(78)3.)

2 Jachuck SJ, Bound CL, Jones CE, Bryson M. Is a pre-employment chest radiography necessary for NHS employees? BMF 1988;296:1187-8.

Krarup KC, Scarisbrick DA. Control of tuberculosis in health service workers: the role of the chest radiograph. F Soc Occup Med 1989;39:128-30.

4 Subcommittee of the Joint Tuberculosis Committee of the British Thoracic Society. Control and prevention of tuberculosis in Britain: and updated code of practice. BMF 1990;300:995-9.

5 Cockcroft A, Chapman S, Insall C, Soper P, Kennard Y, Hollis C. Tuberculin reactivity in new employees in a London Health district. Thorax 1988;43:834.

6 Gatley MS. Tuberculosis in Britain. BMF 1990;300:1339.

7 Cockcroft A, Chaturvedi N, Waldron HA. Tuberculosis in Britain. BMF 1990;300:1723-4.

7 Cockcroft A, Chaturvedi N, Waldron HA. Tuberculosis in Britain. BMF 1990;300:1723-4. $\mathrm{x}$-rays? Occup Med 1992;42:179-182.

9 Burge A, Kumar S, Skinner C. Control of tuberculosis in NHS staff: west midlands 1990-92. Thorax 1993;48:463.

10 Madan I. Pre-employment chest $x$-rays for health service staff: who needs them? $B M$ 1993;306:1041-2.

11 Howell F, Kelly P, Clancy L. Pulmonary tuberculosis in the Republic of Ireland: an epidemiological profile from a single unit. Respir Med 1990;84:111-7.

12 Lunn JA, Mayho V. Incidence of pulmonary tuberculosis by occupation of hospital employees in the national health service in England and Wales 1980-84. I Soc Occup Med 1989;39:30-2.

\section{Correction}

\section{Screening for ovarian cancer}

Owing to an author's error, the cost per case of potentially curable ovarian cancer was reported by Maurice J Webb (17 April, p 1015) as $\$ 1 \mathrm{~m}$. The correct figure is $\$ 44000$. 